Olga GONCHAR, Iryna POLISHCHUK

\title{
INTEGRATION FACTORS OF TODAY AS A PREREQUISITE FOR FORMING A MECHANISM FOR MANAGING THE MARKETING POTENTIAL OF THE ENTERPRISE
}

\begin{abstract}
Preconditions of integration directions of modern business structures, activation of marketing activities, actualization of problems of marketing potential development and ensuring competitiveness are specified.

The principles for building up a mechanism for managing the marketing potential of industrial enterprises are formulated and the scheme of functional components of the introduction of a mechanism for managing the marketing potential is set forth.

The conditions for development of marketing potential and increase in competitiveness of the enterprise are grouped up and the conclusion is made that management of the formation and development of marketing potential of

(C) Olga Gonchar, Iryna Polishchuk, 2019.

Gonchar Olga, Doctor of Economic Sciences, Professor, Professor of the Department of Marketing and Trade Entrepreneurship, Khmelnytsky National University, Ukraine. ORCID: https://orcid.org/ 0000-0003-3917-7586.

Polishchuk Iryna, Candidate of Economic Sciences, Associate Professor, Head of the Department of Marketing and Advertising, Vinnytsia Institute of Trade and Economics of KNUTE, Ukraine. ORCID: https://orcid.org/0000-0001-6939-8529.
\end{abstract}


industrial enterprises should take into account the market conditions and the effect of factors characterizing it.

\section{Key words:}

Market, enterprise, marketing, marketing potential, factors, preconditions, management, competitiveness, development.

JEL: M21, M31, F20.

\section{The Theme's relevance}

The dynamic development of society, the integration of the economy into the world, the European integration of Ukraine, globalization and increased competition, actualize the need for the activation of business activity on the market. Today it is not enough talking about marketing activities. Management should focus on supervising the processes of formation and development of marketing potential of enterprises. Effective marketing potential affects not only the competitiveness and profitability of an enterprise, but also the ability to solve socioeconomic problems, the implementation of requirements for consumer values of goods and services, the quality and innovation of products, and the achievement of strategic goals. The need for studying and considering the factors affecting marketing activities, for the search for new approaches to its improvement are due to the experience of global trends in the theory and practice of management, which define marketing as a special concept of production management and marketing, covering all areas of production and economic activity of enterprises, and marketing information supply. The provision is a coherent basis for the management system. 


\section{Analysis of the recent research and publications}

Autonomous approach to the specification of the object-object and content elements of marketing management theories and the formation of the potential of the enterprise is still prevalent in scientific publications; the issues of optimizing their tools are not sufficiently disclosed, which in the majority of cases reduces the possibilities of the concept of ensuring efficiency, competitiveness and development; the application of marketing management tools in order to obtain a tangible synergy effect, strengthening market positions. Thus, in economic science, there has not yet been a single approach regarding the positioning of marketing potential in the enterprise potential system and the factors that determine it. In the periodical and specific economic literature a lot of attention is paid to the general theoretical problems of marketing and marketing activity of the enterprise, which is revealed in the scientific works of L. Balabanova, A.Voychak, V.Gerasimchuk, S.Harkavenko, Y.U.Dainovsky, D.R. Evans, P. Zavialov, O. Kendiukhova, F. Kotler, I. Kretov, T. Levitta, O. Malysh, M. Oklander, A. Pavlenko, E. Savelyev, G. Savina, G. Semenova, R. Fathutdinova, N. Chukhrai and other authors. The following scientists, such as O. B., Alyochin, Y. Beltyukov, A. E. Voronkova, I. M. Gerasimenko, O. I. Gonchar, I. Z. Dolzhansky, I. A. Ignatiev, I. M. Karapeichik, N. B. Kirich, N. S. Krasnokutskaya E. V. Lapin, O. I. Olesyuk, I. P. Otenko, L. D. Revutsky, I. M. Repin, A. O. Neshykh, A. S. Fedonin, A. V. Cherep and others worked on forming the theory of forming the potential of the enterprise.. However, theoretical and practical work on taking into account the prerequisites and building a mechanism for managing the marketing potential in modern conditions need to be substantiated.

The purpose of the given article is to study the prerequisites and identify the factors for developing elements of the model of enterprises marketing potential management in the current integration conditions.

\section{Presentation of the main research material}

The current stage in the development of entrepreneurial activity in European countries is characterized by overcoming the effects of the global socioeconomic crisis, which has relatively quickly captured the countries of Central and Eastern Europe, resulting in a rapid decline and inhibition of the growth rate 
of the national product. The period of rapid economic recovery has been replaced by a downturn. The socio-economic status of individual countries is different. In 2009 there was a common decrease in gross domestic product, its level is very different: from the catastrophic decline in the countries of the Baltic States and in Ukraine (Fig. 1) to almost zero growth in Poland. The set of problems is most - acceptable - in the countries of Central Europe. The situation in the Balkan countries is somewhat more complicated. It is very complicated in the countries of Eastern Europe and dramatically complex in the Baltic countries. The main factors that threaten the development of the economy in the countries of Central and Eastern Europe can be typologically divided into types: the problems of domestic financing, dependence on foreign conditions, etc. In terms of potential difficulties in the field of internal financing in a better situation today are the countries of Central Europe (the worst situation is only in Hungary), more serious problems threaten the Balkan countries, the countries of the Baltic, Ukraine and Belarus (The Global Competitiveness Report 2016-2017, electronic resource).

Fig. 1

Dynamics of components of the Global Competitiveness Index of Ukraine (according to (The Global Competitiveness Report 2016-2017, electronic resource)

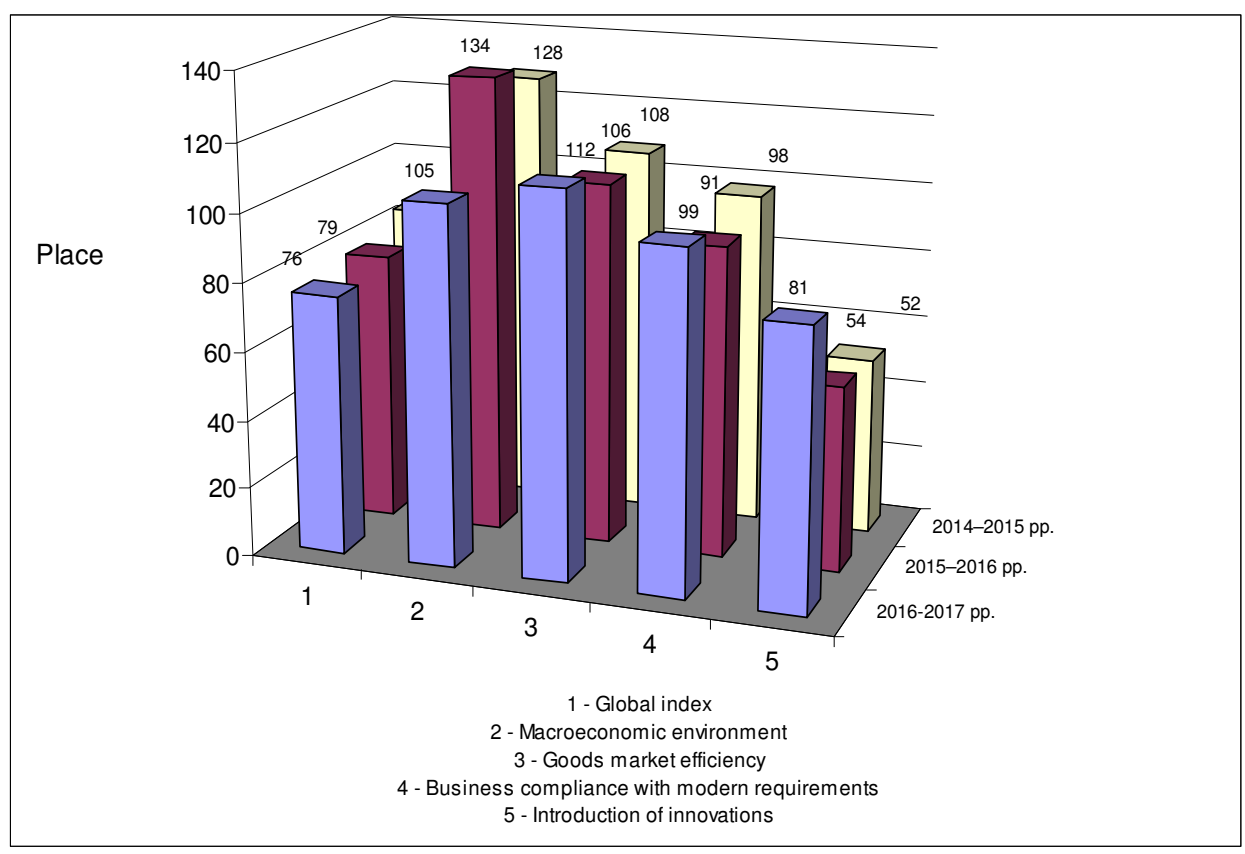


Summarizing existing scholars' assessments of the problems that have arisen in Central and Eastern European countries in connection with the global crisis, it can be stated that Ukraine is in the most difficult situation today. Only balanced and carefully justified economic policy is the key to avoid the problems. It is hoped that the decline in Central and Eastern Europe and, Ukraine, in particular, is of a temporary nature. But overcoming the difficult period and turning to rapid economic growth is impossible without a series of important socioeconomic reforms, the development of international activities that must strengthen the competitiveness of the country, make it more attractive for investment. An effective marketing activity, the formation and realization of marketing potential is of great importance for the identification of potential opportunities, optimization of activities, stabilization of the economic situation of the country and individual economic entities.

The development of transparent economic relations, globalization processes, the ever-increasing competition in the business sector, the constant development and use of Internet resources in all spheres of human life, have led to the need to possess a wide range of knowledge, skills and skills for the immediate response to changes in the external and internal environment (Savelyev, 2012, No. 9, P. 57-69.). In order to develop skills, external and internal economic, social, political and other factors must be taken into account, as well as good knowledge of marketing and understanding of all complexities and their specifics for conducting at the international and domestic levels of business.

For many decades the industry is one of the basic branches of our country. It is the industry, interacting with other industries, determines the level of socioeconomic development of the country and the welfare of society. The results of the conducted researches allow to state that representatives of top management of processing and machine-building enterprises note the weak development of marketing policy at enterprises in the present period. Most often, in the practical activities of industrial companies in the key areas of policy of conquest of the international market, they focus on the processes of mergers and acquisitions, often leaving the important direction of activity, that is the justification of an effective marketing strategy, without due attention.

Today, there are radical changes in economic relations between business entities in Ukraine. The main purpose of transformations is to create a mobile and efficient, capable of independent development of business structures both national and with the attraction of foreign capital. Often this goal is realized through integration. The expediency of the integration process is substantiated by the presence of a number of factors, the entire set of which can be divided into two groups: macro and micro.

The macro-level factors affect the formation of market conditions. They belong to factors uncontrolled by integrated structures. In most cases, their impact is not specific in relation to an individual integrated structure or enterprise that seeks to create it. At the same time, the degree of influence of factors on the 
various integrated structures is diverse and depends on the scope of their activities, as well as the internal potential of enterprises that are part of their composition, the effectiveness of marketing activities.

First and foremost, these factors determining the economic situation in the market, namely inflation rate, tax rates, national currency level, level of interest rate, unemployment rate, nominal and real wages, living wage, etc. Given the stability of the economic situation, effective functioning and development of enterprises of various sizes is possible. If the situation in the economy is not stable, big companies and associations are more stable and reliable. It is easier for them than small and medium-sized enterprises to respond to declining solvency of buyers, rising interest rates on loans, tough loan conditions, non-fulfillment of obligations between counteragents and other negative factors, as their potential and margin of safety is much higher. Illustrates the conclusion and the global financial crisis of 2008, which has challenged the number of small businesses about the possibility of further existence.

Another significant macro-level factor is government policy. Structural transformations in industry are regulated by means of budget, credit, tax, investment, trade and scientific and technical policy, the system of state orders, as well as through the management of state property and levers of administrative control. A wide range of instruments is used for this purpose: direct state capital investments and investments, targeted subsidies, provision of preferential loans, contracts for the development of new products and technologies, direct government purchases of high-tech equipment, protection system, tax incentives and discounts, rules and rates of depreciation, target government programs, etc. The Government, at the various stages of the development of the state, through the listed instruments, creates more favorable conditions for the operation of certain economic entities.

An important factor in the macro level is also innovation and technology. Innovative activity and technology development determine the efficiency of production and sales of goods, the rate of aging of the product, etc. In recent years, the pace of scientific and technological progress and innovation activity are increasing (Fig. 1). At the same time, new technologies are cost-effective. They require large financial investments for a long period of time. Small-scale enterprises of this type of investment are often not available. In such a situation, enterprises are forced to unite in order to be able to switch to output that is in demand and diversify the risks, activate marketing activities for market research.

Micro-level factors direct the management of each enterprise separately until a decision is made on the appropriateness of integration with other business entities in the market and the actualization of marketing activities. The degree of influence of these factors on the results of activities is controlled by the management of the enterprise and depends on the quality and timeliness of management decisions. 
ISSN 2519-4070

Among the main factors of the microlevel, it is necessary to distinguish the following. Financial factors (increasing domestic financial and investment resources, simplifying the procedure for financing research and development of innovations, increasing capitalized value, increasing solvency, obtaining advantages in the capital market, reducing financial risks, etc.). Management factors (demand forecasting, creation of a strong group in the top management of the association, development of labor potential, creation of effective systems of strategic and current business planning, implementation of effective market strategies, expanding resource utilization capacity, improving management efficiency, etc.). These factors are due to the objective need to improve the efficiency of the management system, which is impossible without studying market requirements, effective marketing activities, and application of the principles of economic partnership, the implementation of a holistic innovation-investment, financial strategy, the formation and implementation of marketing potential in a competitive environment.

Economic factors (the effect of reducing transactions, the effect of scale production, expanding experience, streamlining costs, reducing tax burden, growth of cumulative profits, etc.). The main factor that raises competitiveness and strengthens the market position of enterprises is the possibility of obtaining a positive synergistic effect from interaction with market contractors and due to the effective use of various types of resource potential, marketing opportunities. Under modern European integration conditions, it manifests itself in exceeding the effect of the interaction of participants in the integrated structure over the sum of the effects of each participant's activity separately. In integrated structures, synergistic effects include:

- the scale effect - arises as a result of large-scale operations by reducing the value of fixed costs per unit of finished products and services,

- the effect of experience - is the effect of accelerating the implementation of similar operations in a time deficit,

- the effect of complex benefits - means that the package of services, goods or transactions for wholesale supplies is much more attractive than each individual part or amount of individual parts,

- Conglomerate effect - means that increasing the number of divisions distributes the risk between them, thereby reducing it.

Production factors are being actualized (access to scarce natural resources, creation of a reliable and stable system of supply of all kinds of resources, reduction of stocks, the possibility of production of the necessary raw materials and semi-finished products, rationalization of production processes, acquisitions for sharing know-how, patents and licenses, improving product quality, production of large contracts, diversification of production, increase of efficiency of the use of existing production capacities, reduction of production risks 
etc.). By integrating the activities of several enterprises in terms of integration, expansion of production, which will allow the use of more powerful and efficient equipment, may deepen specialization within each structural unit of the integrated structure. In addition, there is the possibility of using the same resource or the same technology simultaneously in several production processes, which ultimately leads to a reduction in the total costs of the integrated structure.

Marketing factors (increase of the controlled market share, expansion, saturation and deepening of the range of product offerings, sharing of sales and after sales systems, distribution of goods under a well-proven brand, the development of new markets, more complete customer satisfaction, accelerating the development and implementation of the market new products, access to more information, comprehensive and large-scale marketing research, uniting efforts to market research and product promotion It, development of strategies to combat competitors, etc.). In modern conditions, the effectiveness of marketing activities and the marketing potential is actualized both for individual enterprises and in integrated structures. The directions of realization of marketing potential are characterized by functional diversity, covering the research, innovation and production-market sphere, orienting them on active and effective formation of consumer value. Effective use of marketing potential creates the possibility of creating unified marketing services that coordinate all marketing activities of enterprises and develop common strategies within each element of the marketing complex.

Foreign economic factors (combining efforts in the development of the international market, stimulating exports and expanding export operations, etc.). The growing level of international competition forces companies to look for ways to unite potentials and cooperate in the struggle for survival or market leadership, the development of market opportunities and marketing potential. Establishment of business partnership relations between companies from different countries and creation of business structures of different degree of integration is one of the most widespread organizational strategies in recent years.

Thus, in order to achieve a positive socio-economic level of development of the country, modern tools for managing financial and economic processes should be used, an important component of which is marketing, which in scientific works of scientists on the essence of origin and concept of formation is investigated as an important tool for the harmonious development of modern society (Fathutdinov, 2000. - 640 p; Stelmha, 2010, No. 1 (26), p. 61-65). Since the main subjects of the market economy are industrial enterprises, the evolution of the production concept in the context of trends in marketing concepts prompts to make a reasonable choice of the needs of consumers of products, to meet them more effectively compared with competitors, with the observance of environmental requirements for environmental protection and effective solution of social problems (Polishchuk, Gonchar, No. 3 (11). Ch. 2 - S. 29-33; Polischuk, 2016, No. 2 (6). - P. 97-102, Gonchar, O. (2017). The complexity of production processes and finished products of machine-building enterprises in conjunction with 
the ecological requirements of the present require systematic conducting of design-search, experimental research, and scientific research (Voynarenko, O.A. Lobko, 2009. - №6, pp. 144-146; Voychak, 2007. - 408 p; Gonchar, 2014, No. 6 (16), P. 199-205).

Therefore, the organization of marketing activities should ensure: adaptation of the enterprise to changing market conditions, individualization of production; the introduction of the latest technologies and innovative production systems that would contribute to the implementation of the requirements of the modern marketing concept to ensure a high image of the company on the market. This requires a high level of competitiveness of the enterprise, which, of course, depends on the level of organization of marketing activities at the enterprises, and is confirmed by the main indicators that reflect the results of their activities and affect the formation and implementation of the aggregate economic potential and the construction (improvement) of the mechanism of managing the marketing potential.

The mechanism for managing the marketing potential of industrial enterprises must meet the following requirements: 1) optimality - that is, the result of activities should be the best among the possible in these conditions; 2) balance, internal coherence and flexibility - that is, timely and adequate response to changes in the environment; 3 ) co-ordination with the costs necessary for the production and implementation of the planned volumes of production.

Taking into account the conceptual foundations of building the mechanism of management of marketing potential and the specifics of its functioning at industrial enterprises, we offer a chain of functional elements of its introduction or improvement, which is presented in Fig. 2.

System-situational approach to the formation of a mechanism for managing the marketing potential of an enterprise implies that all the actual conditions of its activity must be taken into account. The mechanism combines reasonably selected elements, a scheme of their communication and interaction. Only in these conditions, the mechanism will provide a sufficient level of pragmatism and enable the adoption of effective address decisions.

The mechanism of managing the marketing potential of an enterprise can be formed with varying degrees of structuring elements and formalizing the links between them. As can be seen from Figure 2, the factors behind the construction of the mechanism are factors and subjects of the environment that directly or indirectly affect the functioning of the enterprise, its market activity and the peculiarities of marketing activity. The result of the operation of this unit is the receipt of the necessary resources for the organization of the main type of activity of resource and information provision taking into accounts the priority goals of the enterprise. 
Fig. 2

\section{Functional components of implementation of mechanism} for managing the enterprise marketing potential

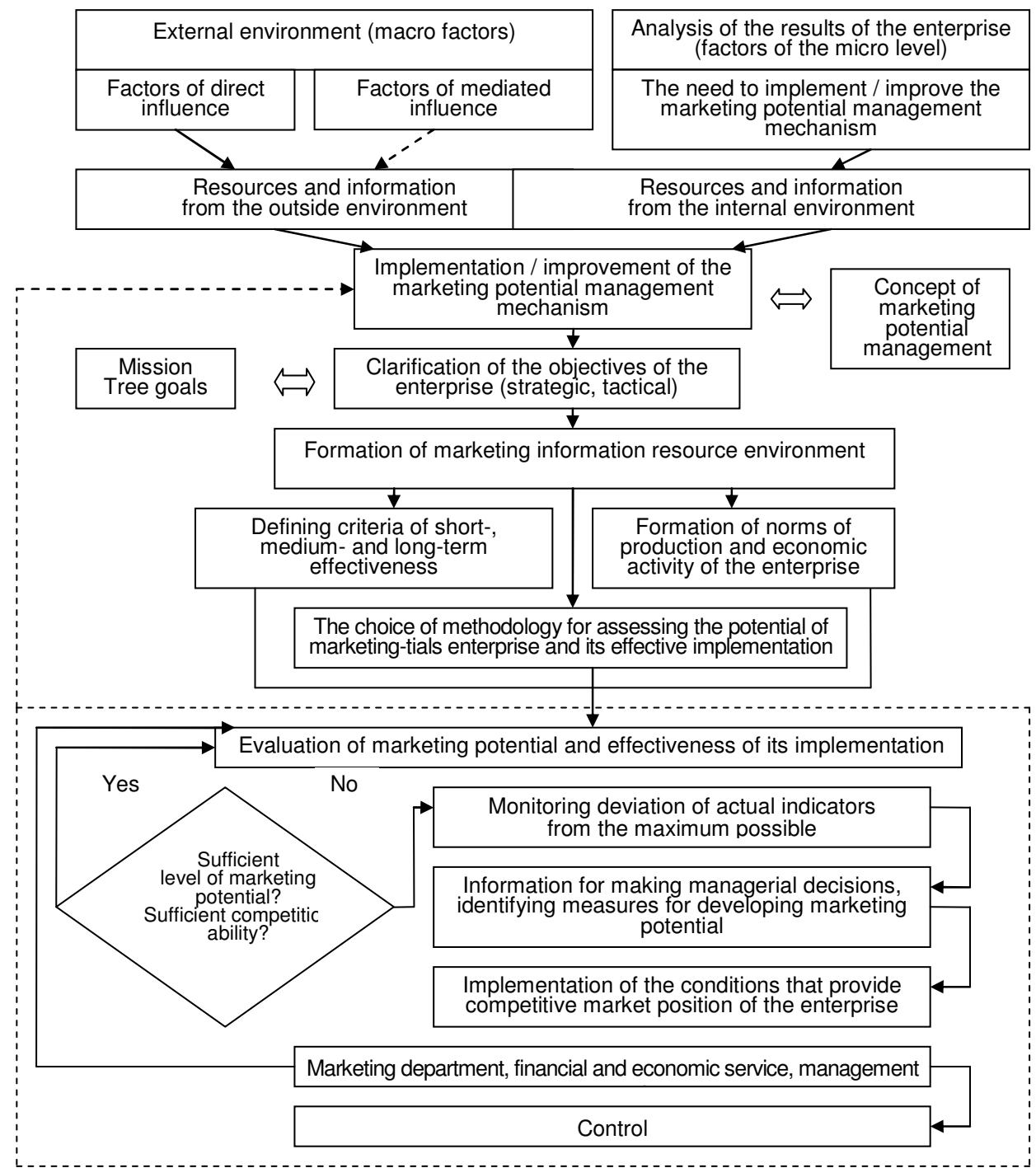


The block of factors of the macro level is aimed at organizing the interaction of the enterprise with the subjects of the environment. The choice of the priority goals and interests allows you to limit the size of the mechanism of managing the marketing potential of the enterprise and focus on it on the key partners for the enterprise. In addition, this block mainly deals with alternative ways of interaction of the enterprise, which increases the flexibility of the mechanism and promotes the implementation of the purpose of the block - minimizing the cost of the enterprise. Alternative interaction of the enterprise with the subjects of the environment is not always possible; sometimes the interaction with suppliers is carried out on a non-alternative basis, for example, with the natural or administrative monopolies of the fuel and energy complex.

Initially, at the level of senior management of the enterprise, the question of the expediency of the implementation of the mechanism is decided. It specifies: 1) recommendations on the basic principles of the formation and functioning of the management mechanism and the direct marketing potential of the enterprise; 2) the purpose of the introduction of the mechanism - to ensure a competitive position in the market, stable operation of the enterprise and optimization of management of resource potential. Then all organizational issues are clarified. Implementation of the mechanism in the management system begins with the specification of the mission of the enterprise and its strategic objectives, taking into account the market situation.

The main unit of the substantiated mechanism involves evaluating the marketing potential and the effectiveness of its implementation. The effectiveness of implementing the marketing potential can be summarized by the achievement of a competitive market position of the enterprise. The result obtained is subject to analysis and interpretation. It turns out which components have influenced its size, how different indicators are from the desirable and the most possible. Information becomes the basis for making managerial decisions on the creation and implementation of the necessary conditions that ensure the effectiveness of the activities related to the formation and implementation of marketing potential (Figure 3).

The most important conditions that are realized in the structure of the mechanism of management of the marketing potential of the enterprise, is the activation of business activity, especially personnel marketing activities; optimization of relations with market contractors; application of effective tools for studying and shaping consumer demand; optimization of information provision, promotion of efficient use of resource potential. It is these conditions that can significantly influence the formation and effectiveness of the marketing potential of the enterprise and ensure competitiveness and development. 
Fig. 3

Conditions for development of marketing potential and increase of competitiveness of the enterprise

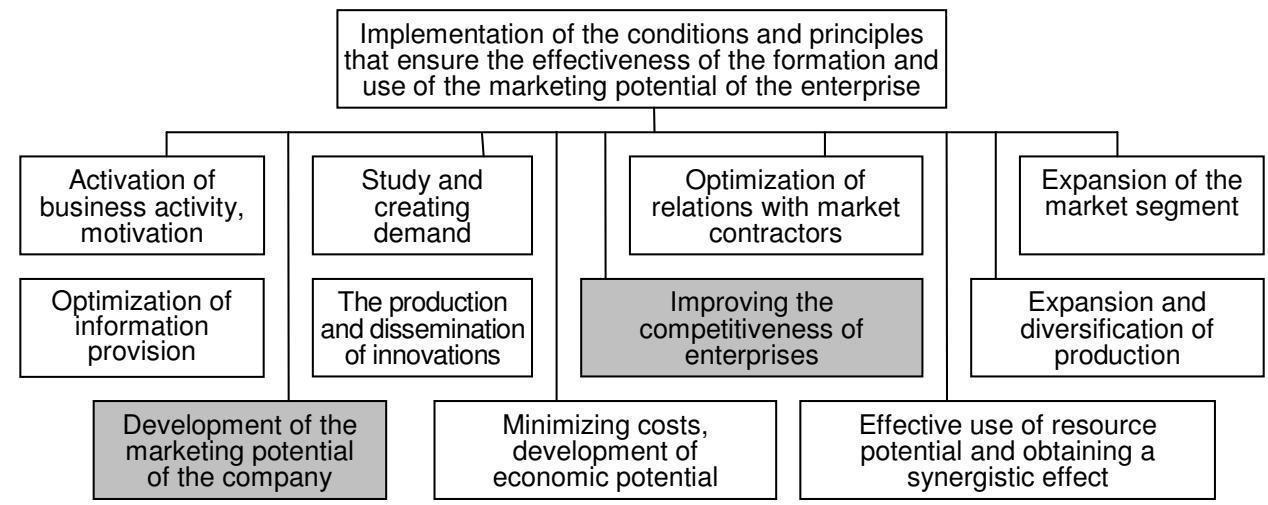

\section{Conclusion}

Consequently, the management of the formation and development of marketing potential of industrial enterprises should take into account the features of the market and the factors that characterize it. Integration directions of the present in this direction should be considered from the functional position and from the point of updating the database and processing information for making marketing decisions using the intellectual component. Therefore, information systems must have the ability to choose integration tools to ensure their functional, informational, technical, programmatic and organizational interoperability.

\section{References}

1. The Global Competitiveness Report 2016-2017 - Retrieved from: https://www.weforum.org/reports/the-global-competitiveness-report-20162017-1 (application date 21.12.2017).

2. Fathutdinov, R.A. (2000). Strategic Marketing: Textbook / R.A. Fattuhddinov $-M$.: ZAO - Business-school - Intel-Synthesis - ,. - $640 \mathrm{p}$. 
3. Stelmha N. (2010). Marketing Communications of the 21st Century / N. Shetlm // Galician Economic Bulletin. -. - No. 1 (26). - P. 61-65.

4. Polishchuk, I. I. (2017). Synergic approach in marketing potential management of the enterprise / O.I. Gonchar, I. I. Polishchuk // Scientific Bulletin Polesie. - Chernigov: CSTU - No. 3 (11). Ch. 2 - S. 29-33.

5. Polischuk, I. I. (2016). Factors of development of marketing potential of the enterprise / I.I. Polischuk // Scientific Bulletin Polesie. - Chernigov: CSTU, No. 2 (6). - P. 97-102. (Professional edition, Web of Science).

6. Gonchar, O. (2017). SCIENTIFIC AND METHODICAL BASES OF PERFECTION ENTERPRISE CAPACITY ASSESSMENT. SCIENTIFIC BULLETIN OF POLISSIA. 2. 134-139. 10.25140/2410-9576-2017-2-1(9)134-139.

7. Voynarenko, S.M. (2009). Theoretical and methodological aspects of marketing research / S.M. Voynarenko, O.A. Lobko // Bulletin of the Khmelnitsky National University. Economic sciences. - - №6. - T.2. - pp. 144-146.

8. Voychak, A.V. (2007). Marketing research: textbook/ A.V. Voychak, A.V. Fedorchenko; for sciences Ed. A.V. Voicheca - K.: KNEU, - 408 p.

9. Gonchar, O. I. (16.06.2018). Prerequisites for the development of a model for managing the potential of enterprises in conditions of uncertainty and risks. O. I. Gonchar // Economics: realities of time / Odessa. nats Polytechnic university. - O., 2014. - No. 6 (16). - P. 199-205. Retrieved from: http://economics.opu.ua/files/archive/2014/n6.html (application date).

10. Savelyev, E.V. (2012). The Impact of Globalization on Ukraine's Economic Development / YE.V. Savelyev // Economy of Ukraine. - No. 9. - P. 57-69. 